\title{
CASE STUDY OF A PROJECT-BASED LEARNING EXPERIENCE AT THE POLYTECHNIC OF VISEU, PORTUGAL
}

\author{
V. Delplancq ${ }^{1}$, S. Amante ${ }^{2}$, C. A. Costa ${ }^{3}$, A. Costa Lopes ${ }^{1}$, E. Coutinho ${ }^{4}$, \\ S. Fidalgo', R. Gillain ${ }^{5}$, P. Lopez ${ }^{6}$, I. Oliveira ${ }^{7}$, J. Pereira' ${ }^{1}$, S. Relvas ${ }^{2}$, P. Roush $^{8}$ \\ ${ }^{1}$ School of Education, Polytechnic Institute of Viseu (PORTUGAL) \\ ${ }^{2}$ School of Technology and Management of Viseu, Polytechnic Institute of Viseu \\ (PORTUGAL) \\ ${ }^{3}$ Agrarian School, Polytechnic Institute of Viseu (PORTUGAL) \\ ${ }^{4}$ School of Health, Polytechnic Institute of Viseu (PORTUGAL) \\ ${ }^{5}$ School of Education and Social Sciences, Polytechnic Institute of Leiria (PORTUGAL) \\ ${ }^{6}$ Universitat Autònoma de Barcelona (SPAIN) \\ ${ }^{7}$ School of Technology and Management of Lamego, Polytechnic Institute of Viseu \\ (PORTUGAL) \\ ${ }^{8}$ London South Bank University (UNITED KINGDOM)
}

\begin{abstract}
Pedagogical innovation is at the centre of higher education (HE) priorities, with a view to renewing its practices and thus motivating students and providing experiences in line with their professional context. Improvement in foreign languages (FL), especially with students who are not likely to receive further language training, requires awareness of this query, inasmuch as competences in FL in the work environment are unanimously recognized as vital and so rightly included in the training plans. The project-based learning approach in an interdisciplinary and collaborative work perspective, using multimodality in communication, is a consistent asset that allows for work to be carried out, comprising the various dimensions of language in French and English, in their connections with cognitive representations. JASM (Open window onto the world: foreign languages, multimodal creativity and pedagogical innovation in higher education) project aims to develop an experience of active pedagogy at the School of Education of Viseu from the Polytechnic Institute of Viseu (Portugal)with undergraduate students in Media Studies enrolled in the various FL curricular units. Among the subjects of the study plan, students work on photography, digital art and cultural communication. The students start off by collecting information on the cultural and linguistic diversity of the city of Viseu (Beira Alta, Portugal). The project enhances the acquisition of multilingual skills and the development of plurilingual awareness, due to the attention given to the various dimensions of language (aesthetic and emotional, in addition to cognitive), in a creative, collaborative and interdisciplinary work environment. Based on an interview, students write the story (in French and English) of the life of migrants. Through captioned photographs, students highlight the aspect of the migrant's family life which stands out the most. Based on an object (associated with religion, a tradition or with a ritual), students create an animated film, also in both languages (exploration of material culture and digital scenography). The outcome of such productions will be the subject of publications on social media, exhibitions, also being displayed at events and in an e-book. In this project, the topic of interdisciplinarity is highlighted, combining FL with digital art. The evolution, both of the students' learning and of the teachers' role in the whole process, is assessed, using tests carried out at the beginning and at the end of the project, including monitoring in the middle of the development of the project.
\end{abstract}

Keywords: Pedagogical innovation, higher education, project-based learning approach, foreign languages and linguistic and cultural diversity, multilingual and multimodal artistic creativity, collaborative and cooperative work, aesthetics and emotion.

\section{INTRODUCTION}

Pedagogical innovation, defined as "the capacity of the system to consolidate change and improvement - to promote experimentation, monitor, evaluate, learn from failures, support networking and exchange, as well as design favourable school policies to help embed, tailor and sustain innovation in school" (Dumcius, 2018, p. 13), is at the heart of Higher Education (HE) priorities. The emphasis is on renewing educational practices in order to motivate students and provide them with 
experiences envisioning their forthcoming professional lives. Innovative approaches improve student motivation and participation, reflection, learning responsibility, opportunity to communicate and allow for teacher engagement and fulfilment as well, because they go beyond ordinary lessons to include all other activities besides lecturing, the method still favoured by Higher Education Institutions (Walder, 2016).

Hence, the teacher's role is changing and nowadays teachers in higher education are constantly forced to follow strategies that focus on the students' autonomy in learning. They must supervise the students in the research process, guide them in the construction of knowledge and skills and not only convey knowledge. In case this does not happen, "then student's learning strategies will be tightly constrained by the views of knowledge and learning they develop from their experience as the 'receivers' of teachers' knowledge", as Harris, Wallace and Rudduck remind us(1995, p. 256).

Learning foreign languages (FL) with students of courses other than FL ones is not exempt from this need to turn students into active learners. Institutional constraints make certain approaches difficult including those pertaining to an improvement of communicative competence and linguistic performance. Project-based learning and the inquiry-based learning are two complementary ways in order to develop communication skills while using transversal and interdisciplinary skills. Direct contact with the real world and objective productions mean that students are involved in collaborative work that evolves according to means, needs and obstacles.

The JASM project was born out of the need to offer students the opportunity to become autonomous learners, empowering them through access to technology and innovative learning experiences. In fact, JASM consists of an open innovation experience (plural and creative approaches to diversity) carried out with students from the Media Studies course (1st and 2nd years) at the School of Education (Portugal). The study plan of this course comprises three years (180 ECTS) which include three compulsory FL curricular units (English and French; 4 ECTS each) and one which is optional (4 ECTS). In addition to the cognitive dimension, students will work on the aesthetic and emotional dimension, through artistic creativity experiences (media arts, multimedia art, among others) in order to practice multimodal communication in English and in French, by collecting information allowing for an understanding of cultural and linguistic diversity patterns and lifestyles found within the city of Viseu. This is very significant since emotion and the arts are not separate from any language; rather, they are characteristics that are inherent to it, as Bonsdorff (2015, p. 108), embracing Merleau-Ponty's thoughts, claims: "Language has a central function in the articulation of emotion rather than in naming emotions; a function it shares with the arts". In an inspiring way, this very same scholar summarises the intimate connection between language and emotion, as follows:

... emotion is part of language in many ways, and can mean many things. (...) Language is at best a flexible, living body of our thoughts and at the same time a structure of our world. Expression in language is therefore not just about our subjectivity; it is also about the world - as it is for us, but that is the only world we have. An insensitive or thoroughly rational language renders a world in black and white; a world with no space for our deviances and improvisations; a world with no space for us; with no space for our love.

(Bonsdorff, 2015, p. 111)

JASM, thus, is a rejection of a black-and-white world, an opportunity for students to express themselves in multiple ways and to share the same space(s), as we will explain in the following sections of this study.

\section{PROJECT- BASED LEARINING AND INQUIRY- BASED LEARNING}

In 2009, in a study by Nóvoa and entitled "Education 2021: Towards a History of the Future", the scholar suggests that the way of conceiving and organizing public education dates back to the 19th century and has shown to be reluctant in its acceptance of "the changes that took place in the course of the 20th century" (p. 3).

Indeed, one cannot ignore the fact that the way labour is organised has completely deviated from the model of the 19th century, and relies today on a logic of project based work and so schools, particularly state ones, must keep pace with these changes, in order to provide students with the necessary tools, so that joining the job market may occur in a natural and fluid way. In this context, project-based learning $(\mathrm{PBL})$ is, in our view, the methodology that best bridges the distance from the school and/or academic environment into the labour sector. 
It is therefore important to take into account the assumptions underlying the methodology under consideration, and in this context, the statements of Haines and Fried-Booth illustrate, in a succinct but clear way, the essence of this approach:

Projects are multi-skill activities focusing on topics or themes rather than on specific language targets. (...) Because specific language aims are not prescribed, and because students concentrate their efforts and attention on reaching an agreed goal, project work provides students with opportunities to recycle known language and skills in a relatively natural context. (Haines, 1989, p. 1)

Project work is student-centered and driven by the need to create an end-product. However, it is the route to achieving this end-product that makes project work so worthwhile. The route to the end-product brings opportunities for students to develop their confidence and independence and to work together in a real-world environment by collaborating on a task. (Fried-Booth, 2002, p. 6)

Bearing upon the statements of Haines and Fried-Booth, it is appropriate to point out some further details and characteristics this methodology entails. In this way, project-based learning is fundamentally aimed at solving problems, so it starts off with real questions/problems, considered to be true for those who will approach them, aware of the fact that there is no simple, objective and unique answer at the outset likely to allow for the resolution and/or immediate clarification of the questions/problems which are being tackled. As Slater et al (2006, p. 242) argue "(...) project-based learning as a social practice requires language and content learning through planning, researching (empirical and/or document), analyzing and synthesizing data and reflecting on the process and product orally and / or in writing, by comparing, contrasting, and justifying alternatives."

As held by Stoller (2006), with a view to accomplishing the intended general objective, it is required that:

- the issues/problems are relevant to those involved in the task(s);

- the information and data collected by small groups is processed and organized, then returning to the larger group - the class;

- all tasks carried out lead to an end-product likely to provide an enrichment of knowledge by the whole class, with regard to the solution of the problems/questions initially posed;

- learning leads to experience; understandable input is received and produced; reports are written; debates, oral presentations, dramatizations are promoted;

- tasks, as a rule, go beyond the limits of the classroom, which not only facilitates, but also presupposes interaction with the community.

In summary, living in a community and being part of the work force means one is part of a group/team. Likewise, project-based learning also requires that one joins a group/team, which develops projects that will lead to the necessary learning processes and end-products, with a view to solving real problems.

In this way, the classroom becomes a space in which the teacher sees him/herself as an advisor, consultant and facilitator, but also as a co-learner. It is, therefore, a space in which hierarchies are fluid and in which the contribution of each one is valued, in order to solve the identified issues/problems.

\section{INNOVATIVE PEDAGOGICAL PRACTICES IN HIGHER EDUCATION}

Teachers in higher education are constantly forced to follow strategies focused on the students. In this sense, it is necessary to promote a behavioural progress among higher education students. Using modern educational methods facilitates student engagement, enhances analytical and innovative thinking, decreases apathy and leads to peer-learning (Santos \& Ali, 2019). The goal is to help students by incorporating authentic study, creation and innovation practices into learning to achieve working life competencies. However, it is difficult for teachers to follow an educational transition from a conventional higher education community to a networked working model (Kunnari and Ilomäki, 2016).

In fact, today's classroom is a challenged and challenging environment, as the centre of the process has shifted from the teachers to the learners (OECD, 2017). 
A key factor that facilitates the process towards active learning, both improving the teaching and learners' engagement, is the possibility of matching the natural inclinations of learners to play, create, express, collaborate and discover, especially because natural learning inclinations go hand in hand with the scientific method, creativity and cooperation (Panigua and Istance, 2018). Among the cluster of active learning strategies, embodied learning connects the physical, artistic, emotional, and social, exploiting two natural dispositions in the learners - creativity and expression, and presents itself as a window for innovation in teaching approaches. It is well reported that dance (together with its reposting), with a public growing attention, an art form that encompasses the physical (movement), the emotional (expression), and creativity (producing dance, choreography), notably relates visual, music, and theatre and promotes the interaction and collaboration with peers (Bradley et al., 2013).

Also, the use of project-based learning and inquiry-based learning provides learners with the experience of leading change in their own settings, building confidence and allows joint learning from each other's experiences.

The combination of different active learning methodologies, such as embodied learning, multiliteracies, project-based learning and inquiry-based learning will allow for/enable an holistic approach, that seems to result better than unconnected practices and techniques (Sawyer et al., 2017; Panigua and Istance, 2018; Sinnayah et al., 2019).

The core link between these methods is the fact that language is an inherent form of expression that relates to each one's identity, feelings, which frame the way people talk, interpret, or raise arguments. In this regard, art and multiliteracies related tasks can benefit from developing language competences, and vice-versa (Rajendram, 2015; Hanemann and Scarpino, 2016 ; Panigua and Istance, 2018).

Nevertheless, research is needed to better understand how these methodologies impact on students learning, which activities may be supported and how they may be implemented, etc, while fetching a continuous cycle of producing hypotheses, gathering evidence and reflecting on where the innovation is up to.

\section{THE CASE OF FOREIGN LANGUAGES AND INTERCULTURAL SKILLS}

As mentioned above, authentic study implies a combination of many interwoven parts, namely creation and innovation practices, but an appropriate setting resembling real life communication, as it occurs in actual interactions, and thus not separate from culture, is of utmost importance. Learning a (foreign) language means opening up possibilities of intercultural exchange. Actually, one can never learn a language apart from the acquisition and development of an intercultural competence, defined by Lasonen (2011, p. 276) as "a broadly understood competence that covers personal characteristics, professional competence and skills, affective domain and cultural education as a whole." That is the reason why the JASM project, described below, has proven to be so significant, since it moves outside the four walls of a traditional classroom to lead the way into the lives of some migrants of different nationalities inhabiting the city of Viseu. The students are, thus, invited to practise language in context, experiencing the challenges and pitfalls of intercultural interactions with an extra motivation and the necessary involvement for learning to occur.

\section{THE JASM PROJECT}

\subsection{Description}

The project's objectives are diverse. At a general level, it intends to develop pedagogical innovation in higher education (HE) in the area of FL in courses other than language courses. One hopes, this way, to contribute to the reflection on the position of the HE teacher with a view to improving the student's autonomy and motivation and strengthening the interconnection between college and the real world. FL learning through social, cultural and artistic stimuli is promoted, through the production of FL content using project pedagogy in the context of linguistic and cultural diversity. It also aims to encourage good interdisciplinary practices to motivate students to develop knowledge and know-how in a collaborative and cooperative manner. One also intends to lead the student to develop a multilingual and multicultural awareness using varied, creative and multimodal approaches.

The JASM project is carried out with students of the Media Studies Course. Career opportunities for these students are in the fields of journalism, production, organization and management of information and institutional and organizational communication. 


\subsection{Methodology}

The course chosen (Media Studies) offers the advantage that the same students study two FL for 4 semesters. Among the subjects the plan of studies comprises, students attend courses in photography, digital art and intercultural communication. In addition to the cognitive dimension, students work on the aesthetic and emotional dimension of language, through experiences of artistic creativity (media arts, multimedia art, photo voice, among others), thus ensuring interdisciplinarity in the course, in order to experiment multimodal communication in English and French through the collection of information on the cultural and linguistic diversity patterns and lifestyles found within the city of Viseu. The way students' learning and teachers' roles evolve throughout the process, is assessed using tests carried out at the beginning and at the end of the project, including half-way monitoring during the on-going period. The teaching staff is made up of FL teachers but also of specialists in digital art, educational innovation and the integration of migrants.

In the first phase, the project was presented to the 1st year students. A first language level test was applied to these students as well as to their colleagues in the class. The test was developed according to the CEFR levels, for written and oral comprehension and written and oral production, and it was inspired by the DELF, DALF and TOEFL tests. Response times were checked for each skills block. In the second phase, five groups of 4 students were formed. Each of the said groups chose a nationality from among a list of local nationalities (references: statistics from the Portuguese Foreigners and Borders Service in Viseu). The nationalities chosen were Angolan, Belarusian, Indian, Italian and Ukrainian. Each group dealt with a nationality other than that of any other group and then carried out a study on the country as well as on the stereotypes associated with nationalities and cultures and illustrative of cultural and linguistic diversity.

Students presented their research in the two foreign language classes to all students attending the same year of the course and this was one of the continuous assessment procedures for the semester.

In addition, an extra photo seminar was held to emphasize specific aspects pertaining tothe photos they would need to take for their assignments.

The groups then had to meet a migrant living in the city. To do this, social networks enabled the exchange of information and the Local Centre for Support to the Integration of Migrants facilitated certain contacts. The objective of the first appointment was to present the project and to conduct an interview so that the students could write the story (in the two FL) of the migrants' lives, as well as to take some photos. Authorization to publish the story and the photos was requested. Through captioned photographs, students tried to show (in their texts written in English and French) important aspects of the life path of the person they interviewed and highlight facets of their personality. These assignments were also presented and commented on during the FL course, in both languages, and were the foundation starting point for the semi-annual students' assessment.

In the third stage, a second evaluation procedure was carried out, based on an exchange of experiences between the students involved in the project and their colleagues, requiring also an explanatory presentation of the work done up to that moment and an ascertaining of their perception of what they had done and their feeling about their progress.

The fourth phase, yet to take place, consists in the creation, by the students, of an animated film, in stop motion, the basis of which will be the choice of an object or a tradition from the chosen migrant family, using both languages (exploration of material culture and digital scenography). The productions will be subject of publications on social networks, exhibitions, projections at events and will be on an e-book. A new evaluation stage is planned to take place at the end of the course.

\subsection{Accomplished and expected results}

In the first phase, after the presentation of the project, twenty students volunteered to join the project team.

The tests developed during the first phase revealed that the average level of English language is B2 and of French is between A2 for speaking and B2 for writing.

In the second phase, the transversal skills acquired in the FL class and in other subjects were mobilized as research was presented resorting to different media, giving a clearly practical dimension to the learning scenario and an opportunity to contact with real life experiences that will be faced by students in their professional career. 
In the third phase, (exchange of experiences) the results were extremely positive. The project learners felt very interested and touched by the people they met and their stories. They even suggested replicating the work but allowing students freedom to choose the general theme. They realise that this strategy motivates them more in the acquisition of knowledge and skills than traditional classes. They appreciate collaborative work and share tasks efficiently and naturally, without conflict. They acknowledge that project-based learning requires more involvement and work. Colleagues find the information shared very interesting but continue to prefer traditional learning and evaluation set at the beginning, as they seem to believe that FL classes should focus on the teaching/learning of language components exclusively, such as vocabulary, grammar, speaking, reading and writing, rather than being concerned also with the development of skills in areas such as research and collaborative work. In this way, as held by Slater et al (2006) "students with this view, therefore, will assess the use of projects negatively as they work though them (...)" (p.245). The conclusions of the 2 teachers of FL directly involved are that the students progress more independently, that they make proposals to develop the work and present them and that they spontaneously make interventions in class to explain the work done and the collected data as well as the problems they faced. In terms of intervention, they guide, suggest and correct all productions, both oral and written.

As for the fourth phase, it is currently being developed as students are selecting materials to develop their work.

\section{REFERENCES}

[1] G. Beckett et al., (Eds.), Project-based second and foreign language education: past, present and future, Connecticut: Information Age Publishing, 2006.

[2] P. Bonsdorff, "Language and Emotion in Merleau-Ponty". In Lüdtke, U. (ed.), Emotion in Language. Amsterdam: John Benjamins Publishing Company, pp. 99-112, 2015.

[3] K. Bradley, J. Bonbright and S. Dooling, "Evidence: A Report on the impact of dance in the K-12 setting", National Dance Education Organization, 2013. Retrieved from https://www.arts.gov/sites/ default/files/Research-Art-Works-NDEO.pdf

[4] R. Dumcius et al.,Study on Supporting School Innovation Across Europe: Final Report to DG Education and Culture of the European Commission. Brussels: European Commission, 2018. Retrieved from https://op.europa.eu/en/publication-detail//publication/2e440297-4ce9-11e8-be1d01aa75ed71a1/language-en/format-PDF/source-70079048

[5] U. Hanemann and C. Scarpino (Eds), Literacy in Multilingual and Multicultural Contexts: Effective Approaches to Adult Learning and Education. Hamburg, UNESCO Institute for Lifelong Learning, 2016. Retrieved from https://docplayer.net/28452315-Literacy-in-multilingual-and-multiculturalcontexts.html

[6] S. Harris, G. Wallace and J. Rudduck, “It's not that I haven't learned much. It's just that I don't really understand what I'm doing': metacognition and secondary-school students", Research Papers in Education 10(2), pp. 253-271, 1995.

[7] J. Lasonen, "Multiculturalism in the Nordic Countries". In Grant, C. \& Portera, A. (eds.), Intercultural and Multicultural Education: Enhancing Global Interconnectedness. New York: Routledge, pp. 261-278, 2011.

[8] B. Lathram et al., Preparing students for a project-based world. Novato, California: Buck Institute Publication, 2016.

[9] A. Novoa, "Educação 2021: para uma história de futuro", Revista Iberoamericana de Educacion, 49, pp.181-199, 2009.

[10] J. Santos, S.A. Figueiredo, M.Vieira, "Innovative pedagogical practices in higher education: An integrative literature review", Nurse Education Today, Elsevier, 72 pp.12-17, 2019. Retrieved fromhttps://edisciplinas.usp.br/pluginfile.php/5004447/mod_resource/content/1/lnnovative\%20ped agogical\%20practices_2019.pdf

[11] T. Slater et al., "Assessing projects as second language and content learning". In G. Beckett et al., (Eds.). Project-based second and foreign language education: past, present and future. Connecticut: Information Age Publishing, 2006. 
[12] F. Stoller et al., "Establishing a Theoretical Foundation for Project-Based Learning in Second and Foreign Language Contexts" In G. Beckett et al., (Eds.). Project-based second and foreign language education: past, present and future. Connecticut: Information Age Publishing, 2006.

[13] I. Kunnari and L.llomäki, "Reframing teachers' work for educational innovation", Innovations in Education and Teaching International, 53 (2), pp.167-178, 2016.

[14] OECD, The OECD Handbook for Innovative Learning Environments, Paris: OECD Publishing, 2017. Retrieved from https://espas.secure.europarl.europa.eu/orbis/sites/default/files/generated/ document/en/9617031e.pdf

[15] A. Paniagua and D. Istance, "Teachers as Designers of Learning Environments: The Importance of Innovative Pedagogies", Educational Research and Innovation, Paris: OECD Publishing, 2018. Retrieved from http://dx.doi.org/10.1787/9789264085374-en

[16] S. Rajendram, "Potentials of the multiliteracies pedagogy for teaching English language learners (ELLs): A review of the literature", Critical Intersections in Education: An OISE/UT Students' Journal, winter, 3, pp.1-18, 2015. Retrieved from file:///C:/Users/HP/Downloads/26307Article\%20Text-61942-1-10-20161104.pdf

[17] J.E. Sawyer, R. Obeid, D. Bublitz, A.M. Schwartz, P.J. Brooks and A.S. Richmond, "Which forms of active learning are most effective: Cooperative learning, writing-to-learn, multimedia instruction, or some combination?", Scholarship of Teaching and Learning in Psychology, 3(4), pp. 257-271, 2017.

[18] P. Sinnayah, J. A. Rathner, D. Loton, R. Klein, and Peter Hartley, "A combination of active learning strategies improves student academic outcomes in first-year paramedic bioscience", Advances in Physiology Education, Volume 43(2), pp. 233-240, 2019.

[19] A.M. Walder, "Pedagogical Innovation in Canadian higher education: Professors' perspectives on its effects on teaching and learning", Studies in Educational Evaluation, Volume 54, pp. 71-82, 2017. 